\title{
ALGUMAS CONSIDERAÇÕES SOBRE A EDUCAÇÃO CLÁSSICA NA INGLATERRA VITORIANA ${ }^{1}$
}

\author{
SOME CONSIDERATIONS ABOUT THE CLASSICAL EDUCATION IN VICTORIAN \\ ENGLAND
}

Renata Cerqueira Barbosa²

\begin{abstract}
RESUMO: A História da Educação Clássica na Inglaterra periodiza seu início na segunda metade do século I d. C. quando o governador romano Agrícola tomou medidas para vincular seus súditos mais perto de Roma. Sob o Império Romano, se estabeleceu um sistema de educação baseado no estudo da imitação dos melhores modelos da literatura, além dos quais, língua e literatura gregas. A Inglaterra do séc. XIX herdou o sistema de ensino da Grammar Schools, mas foi distribuída de forma desigual no país. No início do século, a educação Vitoriana já estava se desenvolvendo nas escolas públicas, mas os métodos de ensino eram diferentes entre as escolas. A escola de gramática sobreviveu desde o Império Romano através da Idade Média e do Humanismo, mas o propósito da instituição começou a ser questionado. Neste sentido, o objetivo deste trabalho é apresentar algumas características e metodologias empregadas pelos vitorianos no ensino da Cultura Clássica, assim como, avaliar a importância dos Estudos Clássicos para a formação da população Inglesa do período.
\end{abstract}

Palavras-chave: Cultura Clássica. Antiguidade. Ensino de História.

ABSTRACT: The History of Classical Education in Britain began in the second half of the first century $A D$ when the Roman governor Agricola promoted actions to maintain their subjects near to Rome. Under the Roman Empire, a system of education based on the study of imitation of the best models of literature had been established, beyond which, the Greek language and literature. The England of XIX century, inherited the Grammar Schools system's, but it was distributed unevenly in the country. At the beginning of the century, Victorian education was already developing in public schools, but the teaching methods were different between schools. The grammar school has survived since the Roman Empire through the Middle Ages and Humanism, but the purpose of the institution began to be questioned. In this sense, our main objective through this paper is to present some characteristics and methodologies used by the Victorians in the teaching of Classical Culture, as well as to investigate the importance of classical studies for the formation of the English population of the period.

Keywords: Classical Culture. Ancient. History education.

\footnotetext{
${ }^{1}$ Este trabalho é parte da Tese de doutorado intitulada: "Concepções da Sexualidade Romana na Inglaterra Vitoriana: A Leitura sobre Ovídio", desenvolvida no Programa de Pós-graduação em História da UNESP/Assis, sob a orientação do Prof. Dr. Hélio Rebello Cardoso Jr, defendida em março de 2011. A pesquisa contou com o financiamento da FAPESP.

2 Universidade Estadual de Londrina. Pós-doutorado UNICAMP.
} 


\section{Introdução}

A História da Educação Clássica na Inglaterra periodiza seu início na segunda metade do século I d. C. quando o governador romano Agrícola tomou medidas para vincular seus súditos mais perto de Roma. Sob o Império Romano, se estabeleceu um sistema de educação baseado no estudo da imitação dos melhores modelos da literatura, além dos quais, língua e literatura gregas. A Inglaterra do séc. XIX herdou o sistema de ensino da Grammar Schools, mas foi distribuída de forma desigual no país. No início do século, a educação Vitoriana já estava se desenvolvendo nas escolas públicas, mas os métodos de ensino eram diferentes entre as escolas. A escola de gramática sobreviveu desde o Império Romano através da Idade Média e do Humanismo, mas o propósito da instituição começou a ser questionado. Neste sentido, o objetivo deste trabalho é apresentar algumas características e metodologias empregadas pelos vitorianos no ensino da Cultura Clássica, assim como, avaliar a importância dos Estudos Clássicos para a formação da população Inglesa do período.

\section{Educar a classe trabalhadora}

É fato que desde a política do "Pão e Circo", é mais fácil controlar uma população alienada no que diz respeito às questões econômicas e sociais, do que ter uma população politizada e instruída. Segundo Edward Thompson (2002, p. 26), o paternalismo antiquado do século XIX queria - dentro dos limites definidos da ordem social - que os pobres continuassem vivendo, trabalhando e se divertindo dos modos que eles mesmos escolhessem.

Alguns seguidores "evangélicos" estavam mais ocupados com a disciplina social e a recuperação moral, classificando os diversos graus de pobres merecedores; justificando os gastos de capital com a caridade em termos de sua taxa de juros, evidenciados por maior empenho, sobriedade, frugalidade e obediência. Até mesmo os reformadores mais bem intencionados viam seus empreendimentos como uma forma de seguro social contra os distúrbios populares. De acordo com Thompson (2002, p. 26), estas reações ficaram tão 
entranhadas na cultura das classes superiores que podemos vê-las revividas incessantemente em cada período de agitação popular no século XIX, durante os movimentos reformistas de 1819 e 1832, o Cartismo e a década de 1880. Podem ainda ser detectadas na resposta que é dada ao "problema" do lazer da classe trabalhadora hoje em dia.

Ainda segundo Thompson, algumas consequências da postura educacional manipulativa empobrecida, malévola e angustiada, foram discutidas por Harold Silver, David Owen, Brian Simon, entre outros, e no campo da educação de adultos do século XIX, por John Harrison. O autor chama a atenção para uma consequência posterior - as cerceadoras limitações de atitude que surgiram entre os homens de educação em relação à cultura e à experiência daqueles que se encontram fora da cultura letrada. Segundo ele, é possível perceber isso claramente se observarmos as reações das pessoas instruídas em relação aos divertimentos tradicionais do povo. Um exemplo citado pelo autor: "Como seria imensamente desejável", conclui o correspondente, que as diversões dos pobres "pudessem ser planejadas de maneira que fossem, ao mesmo tempo, inocentes!" (THOMPSON, 2002, p.31).

O que é frustrante acerca dessa passagem é o medo das espontaneidades populares, o medo da cultura popular autêntica além da manipulação e controle dos seus superiores. - "(..) a peça (...) possa ter uma tendência para lhes causar mal e preparar vocês para as posteriores cenas de agitação e desordem na cervejaria". ${ }^{3}$

Educação e cultura, não menos que os impostos locais para os pobres, eram encarados como esmolas que deveriam ser ministradas ao povo ou dele subtraídas de acordo com seus méritos. O desejo de dominar e de moldar o desenvolvimento intelectual e cultural do povo na direção dos objetivos predeterminados e seguros permaneceu extremamente forte durante a época vitoriana: e continua vivo ainda hoje. De acordo com o autor, a partir de 1790, foi possível ver o que ele chama de "marcha do intelecto", com suas sociedades

\footnotetext{
${ }^{3} \mathrm{O}$ autor relata um diálogo existente numa carta publicada no Monthy Magazine de 1798: "Um amigo dos inocentes divertimentos dos pobres esforçados", entre um minerador que desejava encenar uma peça de teatro num festival anual e uma dama. O conteúdo do diálogo mostra o paternalismo existente entre os patrões e empregados. A razão do operário não poder encenar a peça, é que ela poderia trazer conflitos, ou seja, "depravar tanto a mente dele quanto a dos outros."
} 
de desenvolvimento mútuo, seus institutos de mecânica e suas palestras dominicais, começando a se movimentar. Mas, ao mesmo tempo, ela vai deixando para trás a cultura comum, do povo, baseada na experiência. (THOMPSON, 2002, p.31).

Neste sentido, a tese de Edward Thompson era a de que:

(...) a educação se apresentava não apenas (sic) uma baliza na direção de um universo mental novo e mais amplo, mas também como uma baliza para longe, para fora, do universo da experiência no qual se funda a sensibilidade. Além do mais, na maior parte das áreas durante o século XIX, o universo instruído estava tão saturado de reações de classe que exigia uma rejeição e um desprezo vigorosos da linguagem, costumes e tradições da cultura popular tradicional. (...)(THOMPSON, 2002, p.32).

$\mathrm{Na}$ Inglaterra Vitoriana, o homem trabalhador, que dedicava seus horários de folga à busca do conhecimento, era também solicitado, a toda hora, a rejeitar todo o cabedal humano de sua infância e de seus companheiros trabalhadores como grosseiro, imoral e ignorante. É possível entender as pressões sofridas nesta situação. Segundo Thompson, a realização dos objetivos do movimento da classe trabalhadora exigia novos atributos de autodisciplina, autorrespeito e treinamento educacional. (THOMPSON, 2002, p.32).

Enquanto isto no setor Acadêmico, poucos tópicos da História Intelectual do século XIX têm sido tão negligenciados, como a história do idealismo, após a morte de Hegel. De acordo com Frank Turner, (1993, pp: 322-361) no trabalho da maioria dos historiadores, o idealismo passa a ser deslocado pela ciência e o positivismo de um lado e o marxismo do outro. Porta-vozes do idealismo detinham "cadeiras" de filosofia em praticamente todas as grandes universidades de todo o mundo ocidental; influenciaram a filosofia política e social, contiveram o impacto do utilitarismo e do naturalismo científico, e exerceram influência sobre todas as escolas no início e final do século. Segundo o autor, não houve filosofia idealista única, mas no fim do século o idealismo representou uma visão de mundo que enfatizava as questões metafísicas da filosofia, a análise historicista do passado, o caráter espiritual do mundo, as potências ativas da mente humana entre outros temas. Por outro lado, nenhuma área da vida intelectual vitoriana recebeu tão extensa análise acadêmica como o da "ciência da emergência de modos de pensamento racionalista associados." Esta 
circunstância, em grande medida reflete a expansividade da atividade científica vitoriana, os esforços de profissionalização de seus protagonistas, e o impacto da ciência e da tecnologia na vida cotidiana.

Os defensores da ciência e do racionalismo, seguindo o modelo dos homens contemporâneos de letras, divulgaram suas ideias acessíveis a um público maior nos ensaios de prosa. Poetas, novelistas, críticos literários, filósofos, teólogos, economistas, historiadores, assim como os comentadores políticos e sociais, passaram a olhar para a ciência e racionalismo ou para análises positivistas dos modelos de pensamento progressista e de método. No entanto, uma das arenas talvez inesperada, em que os defensores das perspectivas racionalista e idealista lutaram entre si, foi o da investigação do mundo antigo e mais em particular a da Grécia antiga. Até o final do século XIX, o estudo da história da Grécia antiga, a literatura e a filosofia tiveram mais amplamente associadas com a perspectiva idealista. Esta imagem vitoriana tardia da Grécia enfatizou comunidade sobre o individualismo, o idealismo ético sobre o utilitarismo, a reverência da religião, se sentido bastante liberal, sobre qualquer ortodoxia ou incredulidade, e uma aceitação muitas vezes relutante da democracia temperada pela crença na necessidade de uma liderança bem-educada.

Os gregos tinham demonstrado que sem a revelação cristã ou a tradição da Igreja, um povo poderia permanecer moral e alcançar um impacto duradouro sobre a civilização, sem recorrer ao utilitarismo, o naturalismo científico, o positivismo ou racionalismo crítico. Nas palavras de Turner, (1993, pp: 323325), "o triunfo desta visão idealista da Grécia antiga, que permaneceu comum há décadas em todo o mundo de fala inglesa, tinha sido nada, porém inevitável, e teria sido difícil de prever em meados do século".

Em1911, segundo Thompson (2002, p.35), um ex-inspetor chefe das escolas, Edmond Holmes, lançou em What is and What Hight Be, (p.48) um ataque ao processo educacional. As atitudes determinadas pelo Código Revisto (pagamento por resultados) funcionaram formalmente até 1897 e visava a dominar a criança:

O objetivo do professor é não deixar nada por conta da natureza da criança, por conta de sua vida espontânea, por conta de sua atividade livre; reprimir todos os seus impulsos naturais; domar 
suas energias até uma completa imobilidade; manter todo o seu ser num estado de tensão constante e dolorosa. (THOMPSON, 2002, p.35).

No momento em que a vontade da criança estivesse anulada e ela tivesse sido reduzida a um estado de servidão mental e moral, chegava à hora de o sistema de educação, através da obediência mecânica, ser-Ihe aplicado com todo o rigor. O sistema era visto por Holmes como um engenhoso instrumento para frear o desenvolvimento mental da criança e sufocar suas mais altas faculdades. (THOMPSON, 2002, p.35).

As atitudes em relação à classe social, cultura popular e à educação tornaram-se "estabelecidas" no período que se seguiu à Revolução Francesa. Durante um século, aproximadamente, a maior parte dos educadores da classe média não conseguia distinguir o trabalho educacional do controle social, e isso impunha com demasiada frequência uma repressão à validade da experiência da vida dos alunos ou sua própria negação, tal como a que se expressava em dialetos incultos ou nas formas culturais tradicionais. O resultado foi que a educação e a experiência herdadas se opunham uma à outra. E os trabalhadores que, por seus próprios esforços, conseguiam penetrar na cultura letrada viam-se imediatamente no mesmo lugar de tensão, onde a educação trazia consigo o perigo da rejeição por parte de seus camaradas e a auto-desconfiança. Neste sentido, o impulso oriundo da mesma época chamado de égalité, e com a qual Wordsworth se identificava permaneceu. Porém, para Thompson (2002, pp: 3638), sua fraqueza residia na tendência a considerar o conflito entre educação e experiência como sendo entre o intelecto e o sentimento. Já a oposição entre cultura letrada, intelectual, e a cultura provinda da experiência e de sensibilidade estava sempre presente em Lawrence. Sua questão é exposta da seguinte forma: educação = ideias = classe média; experiência $=$ sentimento $=$ gente do povo. Para ele a classe média só produzia ideias, enquanto do povo provinha a própria vida, calor, seus ódios e amores. Segundo Thompson, o esquema pode ser satisfatório, como uma afirmação em face da fraca cultura literária de Londres, mas dificilmente pode ser considerado uma resolução filosófica válida.

Neste sentido, a reação cultural óbvia a uma cultura letrada manipulativa, de dominação de classe, é a do antiintelectualismo: seja ela militante (como no 
marxismo) ou intolerante (como no movimento Know-Nothing do populismo americano) ou ingênua, presunçosa e sentimental (como aparece com demasiada frequência, na tradição não-conformista inglesa). Isso deve ser encarado como um vício peculiarmente inglês, o qual pode ter influência em parte, na tradição metodista, que ao mesmo tempo em que dava apoio ao igualitarismo espiritual, se afastava das tradições intelectuais mais rigorosas das primeiras igrejas dissidentes.

Ao oferecer algumas sugestões a respeito da alienação das culturas, Thompson (2002, pp: 41-42) afirma que a antiga cultura popular paroquial há muito desapareceu e a cultura do trabalhador, mais articulada politicamente, que a sucedeu nos centros industriais, perdeu sua vitalidade gradativamente. Os educadores resistiram e repeliram com sucesso - especialmente na educação elementar - as manifestações de pior qualidade para a dominação cultural e o controle social. No entanto, o impulso na direção do igualitarismo cultural associado à Wordsworth, foi ameaçado gradativamente, devido às necessidades de uma sociedade industrial adiantada, juntamente com as pressões pertinazes do movimento político trabalhista, levando a uma ampliação das oportunidades educacionais do povo, a qual passou a ser vista em grande escala, simplesmente como um instrumento de mobilidade social seletiva. Além do mais, seja qual for o método de seleção, todo o sistema trabalha de modo a confundir certos tipos de capacidade ou facilidade intelectual com realização humana.

A aprovação social do sucesso educacional é assinalada de uma centena de modos: o sucesso traz recompensa financeira, um estilo de vida profissional, e prestígio social, se apoiando numa apologia completa da modernização, necessidade tecnológica, bem como, igualdade de oportunidades. Esses avanços acarretam uma "traição" fundamental ao tipo de igualdade de mérito que Wordsworth imaginava. A cultura letrada não está isolada em relação à cultura do povo à maneira antiga de diferença de classes, mas, não obstante, está isolada dentro de suas próprias paredes de auto-estima intelectual e de orgulho espiritual.

Um debate também é travado na imprensa pelos educadores que atuam na formação de adultos dos meios populares, sobre as visões contraditórias da pedagogia a ser adotada. A primeira opção tem a simpatia dos partidários de 
uma modernização da educação popular preferencialmente vinculada ao estilo universitário e centrada nas artes e nas letras. A outra linha, mais apoiada em realidades regionais, valoriza as tradições puritanas do movimento operário e milita em favor de uma abordagem sociológica em sentido amplo, apoiando-se na economia, na filosofia e na política e buscando mobilizar as pessoas mais avançadas da classe operária para formar quadros.

Segundo Mattelart e Neveu, o tema de uma democracia de trabalhadores contra uma aristocracia de letrados é recorrente no debate. Os partidários das letras censuram à visão sociológica o fato de ela permanecer cega às formas das mensagens e da cultura. Para além de suas contradições, Thomas Carlyle e Matthew Arnold entre outros, dividem um questionamento sobre o papel da cultura como instrumento de reconstituição de uma comunidade, de uma nação, em face das forças dissolventes do desenvolvimento capitalista. Os estudos culturais participam desse questionamento, optando de modo decisivo por uma abordagem via classes populares. (MATTELART \& NEVEU, 2004, p.40).

\section{Os estudos clássicos na Inglaterra}

Duas tradições opostas podem ser encontradas na história do ensino ocidental, ao retomarmos o passado. A primeira diz respeito à criança grega, que aprende de cor os poemas homéricos e se prepara, em seguida, para a formação retórica, para a eloquência e para a tribuna; a segunda dedica-se aos poetas da cidade, denuncia os artifícios da sofística, que ensina provar tanto algo como seu contrário; além disso, coloca em primeiro plano o ensino e a prática da filosofia. Esse debate presente na Grécia antiga conhece numerosos prolongamentos no curso da História, sob diversas formas. Não foi apenas a noção de filosofia que se ampliou para novas concepções de mundo - ou ligadas ao cristianismo, como a escolástica, ou relacionadas a características do mundo moderno, como o pensamento científico - mas também o patrimônio literário escolar enriqueceu-se e diversificou-se, adotando como suporte de duas a três línguas clássicas. De acordo com Chervel e Compère, essa dupla tendência aparece ao longo da 
história da Pedagogia, embora com deslocamentos (CHERVEL; COMPÈRE, 1999, pp. 149-170).

Segundo esses autores, em épocas diferentes e até em mesma época, dois tipos de formação são oferecidos à juventude de classes dirigentes ou classes abastadas:

uma fundada sobre a natureza, sobre as coisas e sobre o universo, permitindo ao homem se situar no mundo, nele multiplicar suas marcas, índices, inscrever sua ação. A outra apoiada em textos de longa duração e sobre a língua necessária à comunicação, à persuasão, suporte indispensável, até mesmo consubstancial do pensamento. A língua integra o indivíduo em uma elite, em uma nação, em uma cultura, que ele partilha ao mesmo tempo com seus ancestrais e com seus contemporâneos. (CHERVEL; COMPÈRE, 1992, p. 149)

$\mathrm{Na}$ educação inglesa, predominou a segunda tradição, que pertence às chamadas humanidades. A História da educação clássica na Inglaterra, segundo Clarke, (1959, p. 1-3) teve seu início em "78 d.C. quando o governador romano Agrícola, após sucessos militares espetaculares com os quais seu governo começou, tomou medidas para vincular seus súditos mais perto de Roma". Sob o Império Romano, se estabeleceu um sistema de educação baseado no estudo da imitação dos melhores modelos da literatura, além do qual, língua e literatura gregas.

A Gramática grega começa com Homero e Menandro entre outros e a Romana se concentrou em Virgílio, Menandro Romano e Terêncio. De acordo com Clarke, (1959, p. 1-3) Salústio foi lido nas Escolas no Império Tardio, porém, por outro lado, a escrita em prosa foi geralmente ignorada. A tradição da escola romana, embora sobrevivesse levemente, estava muito enfraquecida na Idade Média, no entanto, não houve falta de escolas secundárias e, apesar de evidências sobre o currículo serem escassas, ao que parece, nestas escolas o aluno poderia ler algumas obras de Ovídio e Virgílio, além de poder compor versos latinos.

Na opinião de Chervel e Compère (1999, p. 149), do "homem honesto" da Antiguidade Clássica ao "homem cultivado" da época contemporânea, o indivíduo que essa tradição forma é aquele que, devido à prática dos textos e dos autores, ao contato com as civilizações fundadoras, por meio do exercício da tradução, da 
imitação e da composição, adquiriu o gosto, o senso crítico, a capacidade de julgamento pessoal e a arte de se exprimir oralmente e por escrito, conforme as normas recebidas. Esse ideal visado provavelmente conheceu, no decorrer dos séculos, diversas definições. O homem que se enquadra nesse horizonte das humanidades foi o cristão do colégio jesuíta, o cidadão das luzes, o republicano dos liceus modernos, ou o gentleman vitoriano. Nesse sentido, no ensino tradicional inglês, as humanidades clássicas se definiam por uma educação estética, retórica, mas também moral e cívica.

As humanidades remontam, sem interrupção, às artes liberais antigas. 0 modelo de formação proposto foi fixado por Isócrates ${ }^{4}$ na Atenas do século IV a.C e posteriormente herdado pelos romanos. Segundo Chervel e Compère (1999, p. 150), no conteúdo escolar, elas constituem a quase totalidade do ensino de $5^{a}$ a $8^{a}$ séries até meados do século XIX, ao menos nos cursos tradicionais. A literatura latina, ou seja, os autores romanos e os exercícios de composição em latim constituíram seu eixo.

No que diz respeito à palavra humanidades, a etimologia do termo combina diversas filiações ou contaminações lexicológicas. A primeira remete-nos ao neologismo humanitas ${ }^{5}$. A educação, assim oferecida, tem por objetivo uma

\footnotetext{
${ }^{4}$ Segundo Moses Finley, Isócrates "tem arcado, por mais de dois mil anos, com a culpa de ter sido o homem que implantou o ponto de vista retórico... na política, na educação e na historiografia". Daí em diante a retórica ocupou lugar de honra na instrução superior, num esquema que logo foi canonizado no que os romanos chamaram as sete "artes liberais". Os quatro estudos preliminares compreendiam o que Isócrates denominava de "ginástica da psique", matemática subdividida em aritmética, geometria, música (ou harmonia) e astronomia. As três disciplinas avançadas destinavam-se ao ensino do bem falar e da persuasão: gramática, que era uma combinação do estudo da linguística e da história da literatura, retórica e dialética. Esse princípio passou dos gregos antigos para o mundo bizantino e dos romanos para o oeste latino (FINLEY, 1989 , p. 215).

${ }^{5}$ Segundo Maria Helena R. P., Humanitas deriva de humanus, que por sua vez está relacionado com homo ("o homem") e humus ("a terra"). O verso de Terêncio é um dos mais citados para explicar o sentido de Humanitas: Sou homem; nada do que é humano tenho por estranho. Portanto, tem-se a noção de "ser terreno" ligada à de modos de comportamento que Ihe são próprios, e esta ligada à de um conjunto mais vasto que transforma num conceito englobante - 0 de humanitas. (...) Mas humanitas não é para os antigos, senão tardiamente, o conjunto dos homens, como se pode ver nestes exemplos de Cícero: Quem há aqui que ignore que a força principal da eloqüência reside em incitar o espírito dos homens à ira, ao ódio, ou à dor, ou em reconduzi-los, dessas mesmas paixões, à brandura e à misericórdia? Efeitos esses que, se não se estudar a fundo a natureza dos homens e todo o valor da humanitas e as causas que excitam ou acalmam os espíritos, nunca se alcançarão pelo discurso. Já na Defesa de Séstio, peça fundamental para a história do pensamento político romano, os homens, a princípio dispersos e violentos, tinham aprendido a viver em cidades, a obedecer à justiça e a usar a mansidão. (...) Ora, entre esta vida polida pela humanitas e a outra, cheia de crueldade, nada se opõe tão marcadamente como o direito e a força. Se não quisermos servir-nos de um, teremos de utilizar o outro. Essa humanitas já é civilidade, que se opõe à crueldade primitiva, desconhecedora do
} 
preparação do indivíduo ao seu papel de homem, no sentido pleno do termo. A segunda vem da tradição cristã, que distingue as litterae humaniores ${ }^{6}$ das litterae divinae ou sacrae, do mesmo modo como a literatura profana distinguese da Escritura. A tradição cristã, segundo Chervel e Compère, evidencia o caráter eminentemente laico das humanidades. O terceiro componente semântico do termo faz referência aos humanistas. Nascido no berço da Renascença, não é por acaso que humanistas designa ao mesmo tempo, os escritores da Antiguidade Clássica e os alunos das novas classes, que abordam os temas relativos às humanidades. Segundo os autores, na origem, o nome de humanidades foi dado pelos jesuítas aos estudos intermediários entre os de gramática e retórica.

As escolas de gramática permanecem como uma herança na Inglaterra do século XIX. De acordo com Clarke, essas escolas estavam distribuídas de forma desigual em todo o país, apoiadas por doações e regidas pelos estatutos datados em muitos casos, desde a época dos Tudor. No início do século, o sistema de ensino público que iria dominar a educação na era vitoriana já estava começando a se desenvolver. Algumas escolas, como Eton e Winchester, por exemplo, sempre foram internatos, outras, devido às doações valiosas e bons diretores entre outros motivos, obtiveram um bom desenvolvimento, o que levou à procura de alunos de todo o país e não só da região. Porém, tanto no currículo quanto nos métodos de ensino houve pouca diferença entre uma escola e outra. A partir deste ponto de vista Eton foi apenas a maior e mais importante dentre as escolas de gramática. (CLARKE, 1959, p. 74).

É fato que as escolas tradicionais costumavam exercitar os filhos dos ricos em gramática latina. De acordo com Beard e Henderson (1998), cem anos antes, ou seja, no final do século XIX, a maioria das escolas públicas britânicas ensinava pouco mais que grego e latim. A justificação para isso não era primordialmente a excitação que a literatura antiga oferecia a um aluno capaz de ler fluentemente essas línguas, mas os hábitos lógicos e racionais que supostamente lhe seriam inculcados pelo cuidadoso aprendizado das regras gramaticais. Constituiu uma pequena indústria vitoriana a produção de livros-texto (alguns ainda em uso)

direito (PEREIRA, 1989, pp. 417-419). Outro estudo sobre o conceito está presente em Veyne, "HUMANITAS: Romanos e não romanos" (In: GIARDINA, 1992, PP: 283-303).

${ }^{6}$ Os autores Chervel \& Compère, citam como exemplo a Ratio Studiorum jesuítica. 
para elucidar os pontos mais sutis dessas regras, classificando e descrevendo as partes gramaticais:

o gerúndio e o gerundivo, amo-amas-amat, o ablativo absoluto, o discurso indireto, a forma condicional em oratio obliqua, os verbos em -mi, a terceira pessoa do singular do mais-que-perfeito passivo do subjuntivo da quarta conjugação.(BEARD; HENDERSON, 1998, p. 133)

A Gramática teve indubitavelmente importante significado no que diz respeito ao latim e ao grego no momento em que a maioria dessas escolas foram fundadas e, apesar das mudanças que tiveram lugar no ensino do Latim ${ }^{7}$, desde então, a lei ainda exigia que eles realizassem a intenção de seus fundadores. Desta forma, os clássicos devido a sua posição na educação, separam e classificam as antigas fundações e no início do século XIX, muitos estavam provocando a morte de parte do passado.

Além da demanda por uma educação utilitária para aqueles que não tinham a intenção de serem admitidos para uma formação em sua profissão, havia dúvidas sobre o valor de uma dedicação exclusiva ao estudo e à imitação dos antigos poetas. Desta alteração, o mais importante foi a mudança de interesse do latim para os autores gregos. A literatura latina foi pouco considerada na Inglaterra do XIX, principalmente na primeira metade. A primeira importante influência no ensino clássico no séc. XIX foi Samuel Butler quem fundou Shrewsbury School (provavelmente em 1798) e se tornou a principal liderança da escola clássica no país. Ele inclui Tácito e Cícero no currículo e B. H. Kennedy recorda Demóstenes, Tucídides e Platão. Butler ensina também história antiga e geografia, o que era negligenciado antes deste período. (CLARKE, 1959, p. 7476).

Enquanto as escolas públicas e as escolas dotadas de gramática foram os principais redutos dos clássicos, havia no início do séc. XIX, uma série de escolas privadas que preparavam para a Universidade e deram uma educação clássica em linhas de Liceu. Mais tarde, esses estabelecimentos tendiam a desaparecer e no meio do século, uma escola privada em geral foi uma escola não-clássica ou semi-clássica. (CLARKE, 1959, p. 82).

\footnotetext{
${ }^{7}$ Houve certo abandono da língua latina em detrimento da grega.
} 
Esses acontecimentos estão envolvidos em um contexto de surgimento das humanidades modernas, cuja temática está no centro do debate pedagógico do século XIX e reivindicam o estatuto de produtoras de cultura geral, o qual se assemelhava ao das línguas antigas. Partindo da argumentação das línguas clássicas, enfatiza-se a importância do ensino das línguas e das literaturas, assim como o papel decisivo dos exercícios de versão, tradução e composição para a formação tanto linguística quanto intelectual do aluno. As línguas antigas são aos poucos substituídas pelas línguas modernas e, no lugar de Homero, Demóstenes, Virgílio e Cícero, utilizam-se Shakespeare, Goëthe, Dante e Cervantes (CHERVEL; COMPÈRE, 1999, p. 166).

Em 1860, pela primeira vez, o governo começou a se interessar pela educação secundária na Inglaterra e País de Gales. Em 1861 a Royal Commission sob o comando de Lord Clarendon apontou um inquérito sobre o estado das escolas públicas. Os relatórios dessas comissões, publicados em 1864 e 1868 respectivamente, deram um retrato valioso do estado da educação clássica no meio do período Vitoriano. A característica mais marcante no "quadro" é a diminuição das velhas escolas de gramática (Liceus). De acordo com o Schools Inquiry Commission, $27 \%$ das escolas de gramática tiveram as escolas clássicas completamente; $23 \%$ foram semi-clássicas, mais latim e pouco grego e $43 \%$ nem latim, nem grego. (CLARKE, 1959, p. 85).

Outro estudo descobriu que não havia meninos que com qualquer quantidade de tempo e uso ilimitado do dicionário pudessem traduzir com exatidão digna, uma passagem normal de Cícero e Virgílio. Neste sentido, observa-se que a demanda da educação clássica variava em diferentes partes do país. Em Devon os fazendeiros e homens de negócios preferiam o Latim e não o Grego, pois o Latim era citado muitas vezes nos jornais. Já em Westmorland e Cumberland era um tanto peculiar, pois eles eram normalmente bem abastecidos com as escolas de gramática e no início do século havia um conhecimento amplamente difundido dos clássicos nesses municípios. Em outra parte do país, as "classes mercantis e comerciais", e, em geral aqueles cujos filhos não eram susceptíveis de aprender uma profissão ou continuar os estudos após a idade de dezesseis anos, não tiveram nenhum uso para o grego e talvez um uso tolerado do Latim, mas em qualquer caso, opuseram-se à educação exclusivamente clássica oferecida pelas escolas de gramática. Como consequência, inúmeras escolas particulares tinham surgido para atender às demandas dos pais que 
consideravam os clássicos inúteis. (CLARKE, 1959, p. 86-87). Nas palavras do autor:

O espírito da época era utilitarista, as vastas populações das novas cidades industriais julgavam a educação exclusivamente pela sua utilidade e tiveram como seus porta-vozes, homens como Cobden, que declarou que um exemplar do The Times continha informações mais úteis do que o conjunto de Tucídides. (CLARKE, 1959, p. 8687).

Com o passar do tempo, as escolas de gramática perderam terreno, não só para as escolas privadas, como também para as escolas públicas, pois uma clara distinção entre estas e as escolas de gramática foram perceptíveis. A educação clássica, como a Comissão de Inquérito Escolar colocou, a cada dia e em maior grau, sofreu com a evasão da pequena escola de gramática para as grandes escolas públicas.

A própria centralidade da Grécia e Roma no ensino secundário e superior provocou um processo natural de reação. De acordo com Norman Vance (1997, p. 3), o lento mas inevitável eclipse dos clássicos pode ser datado a partir da década de 1860 com o relatório reformista da comissão de inquérito das escolas. Afinal, a "reforma" foi um dos lemas do século XIX. No entanto, onde as questões relativas a Roma haviam sido abordadas "sem imaginação", ou onde haviam sido selecionados determinados aspectos com o objetivo de reforçar tendenciosamente (e geralmente de forma machista) noções como, por exemplo, de justiça implacável do imperialismo desenfreado, era inevitável que essas versões de Roma fossem desvanecer-se. Destarte, progressivamente homens e mulheres vitorianos descobriram que eles ainda poderiam derivar de estímulo de outros aspectos da experiência romana.

Segundo Vance (1997, p. 4), num momento em que os vitorianos de créditos próprios, os tecnocratas e cientistas viam a modernidade em apuros no sentido de avanços científicos e tecnológicos, estabeleciam as suas credenciais de troça dos clássicos, principalmente no que dizia respeito à educação e literatura clássicas. Nesse sentido, revisores progressistas de Edimburgo, incluindo o matemático John Playfair, desprezaram o currículo predominantemente clássico de Oxford como um instrumento educativo de utilidade duvidosa. No entanto, segundo o autor, os clássicos revidaram, e o 
debate permaneceu em curso por mais de quarenta anos. Mas a sobrevivência dos romanos, pelo menos, não era apenas uma questão "de poucas orelhas em textos de graduação". Os romanos eram um povo prático, como os vitorianos, com sucesso de soldados, engenheiros e administradores. Foi difícil para os matemáticos ou engenheiros repudiá-los completamente, mesmo em nome do progresso ou da tecnologia, quando os edifícios elaboradamente construídos, muralhas e estradas evidenciavam que o avanço tecnológico romano ainda era visível após tantos séculos.

O velho fascínio com a antiga Roma continuou a florescer dentro e fora do século XIX, não apenas sobrevivendo ao lado, mas, em alguns casos, colaborando poderosamente com uma política e cultura que colocaram um prêmio elevado na modernidade, progresso e reforma. A enorme popularidade de Macaulay (autor de Lays of Ancient Rome - 1842) ajuda a demonstrar que a antiga Roma, diversamente construída ou reconstruída, poderia não ser apenas parte do passado morto, mas uma visão e uma ideia que transcende seu contexto original: na política e na esfera privada, na vida e na literatura, Roma apresentou paradigmas desafiadores e pontos de referências, formas de tornar a sensação de um presente caótico e volátil em modelos possíveis para o futuro não revelado (VANCE, 1997, pp. 4-5).

Nesse contexto de mudança, na visão dos vitorianos a respeito dos clássicos e da necessidade de afirmação de outras disciplinas, muitas universidades mantêm o classismo, mas com ênfase em outras áreas. Segundo Vance, Mandell Creighton (mais tarde bispo de Londres e historiador do papado) escreveu uma carta a seu filho, em 1888: "a razão pela qual os meninos são ensinados latim e grego é porque o aprendizado dessas línguas é o melhor exercício de cuidado, atenção, precisão, rapidez de percepção, e tais qualidades como estas." Essa passagem demonstra o porquê da permanência dos clássicos em algumas universidades. No entanto, percebemos que os clássicos não haviam sido mantidos da mesma forma. De acordo com Clarke:

(...) em outro lugar o que tinha sido no dia anterior a delícia dos meninos mais talentosos se tornou um fardo. A influência das universidades deve ter ajudado a "matar" a composição original para que houvesse medalhas e prêmios para tal composição, e, 
embora ainda fossem necessárias as bolsas de estudo nas universidades, isto não tinha lugar no $\operatorname{Tripos}^{8}$ ou no Oxford Honour Schools. (CLARKE, 1959, p. 92)

A Cambridge Classical Tripos foi criada em 1879. A estrutura de seus cursos, suas fronteiras disciplinares e - no jargão moderno - seus princípios gerais de progressão do estudante foram originalmente definidos em uma série de propostas aprovadas pela Universidade naquele ano. O esquema deles dividiu a Tripos em duas partes. Parte I enfatizou as competências lingüísticas e de tradução; Parte II (que se manteve até 1918 como opcional) ofereceu aos alunos a oportunidade de trabalhar em uma ou mais das sub-disciplinas especializadas que compõem os estudos Clássicos.

Segundo Mary Beard a impressionante série sem imaginação, do que foi usado para identificar os diferentes ramos do assunto na Parte II são aqueles que ainda são usados no Tripos hoje: A para a Literatura, B para a Filosofia, C para a História, D para a Arqueologia e E para Filologia e Lingüística. E estes, são as especialidades que hoje geralmente são consideradas como componenteschave da aprendizagem clássica como um todo, tanto em Cambridge quanto em outros lugares. (BEARD, 2001, p.89).

Existem poucas maneiras melhores de apreender a essência de um autor do que pela tentativa de expressar as suas palavras em uma língua estrangeira, e provavelmente há muitos que aprenderam mais sobre a literatura Inglesa a partir de suas composições clássicas do que de suas aulas de Inglês. Isso, no entanto, significaria pouco para os meninos menos talentosos, que simplesmente não poderiam fazer versos.

A composição do verso latino ainda era quase universalmente considerada como uma parte essencial da educação. Nas Escolas Públicas o verso era obrigatório, e para a maioria era um fardo doloroso e inútil. Assim, a composição de versos começou a perder a sua antiga posição como uma parte essencial da educação Inglesa.

\footnotetext{
${ }^{8}$ O Tripos Clássico da Universidade de Cambridge era equivalente ao curso de graduação Alíneas Humaniores da Universidade de Oxford. Era tradicionalmente um curso de três anos, no entanto para aqueles que não têm estudado latim e grego na escola foi introduzido um curso de quatro anos. Não era essencial ter um grego de nível A para fazer o curso de três anos, pois o ensino intensivo grego estava disponível, mas a maioria dos estudantes teriam um nível A em latim. 0 ensino dos clássicos em Cambridge consistia de linguagem (grego e latim), literatura clássica, história antiga, arte e arqueologia clássica, filosofia clássica e llinguística.
} 
Outra mudança que marcou a educação clássica no fim do séc. XIX foi o desenvolvimento de edições detalhadas. Na primeira parte do século foram utilizados textos simples ou edições que quase deram o tipo de ajuda que um estudante moderno precisava. Os melhores estudiosos floresceram sob a disciplina de abordar um texto simples de Platão ou Tucídides apenas com a ajuda de dicionário e gramática, e não poderiam conciliar-se a comentários. (CLARK, 1959, p. 93).

Enquanto os melhores trabalhos de aprendizagem foram feitos em Latim e Grego, havia claramente uma boa razão para o estudo dessas línguas. Mas poderia muito bem ser perguntado por que eles foram estudados como foram; por muito tempo o estudo foi dedicado à leitura dos poetas e da imitação da elegância do estilo clássico. A resposta seria que, como Erasmo diz, o conhecimento das palavras é essencial para o conhecimento das coisas, assim como a melhor maneira de adquirir um conhecimento de uma língua é lendo bons autores.

Os autores a serem lidos primeiro foram aqueles cujo estilo era o melhor e que iria atrair o leitor pelos encantos do assunto. Os encantos de Terêncio, Ovídio e os Eclogues não eram tão facilmente apreciados pelos jovens, no entanto, não deveríam subestimar o seu recurso em uma idade que não estava prevista assuntos abundantes em vernáculo ou outro material de fácil leitura. Além disso, eram valiosas as lições de moral a ser aprendida a partir da literatura antiga, não só nas obras dos professores filósofos e moralistas, mas também escritores que tiveram por objetivo nos entreter, mas que poderia ser feito para render lições de moral a uma idade determinada a encontrá-los. Não havia nenhuma disposição do cristianismo. O ideal era uma combinação de boa literatura e religião, a pietas literata da Renascença do Norte. (CLARK, 1959, p. 167).

A atitude dos homens do século XIX em relação aos clássicos mudou ainda mais, e novos argumentos foram usados para justificar uma educação clássica. Algumas destas justificativas tinham uma validade temporária, tal como o argumento de que os clássicos foram o único tema que os homens sabiam como ensinar e para o qual os professores estavam disponíveis, enquanto outros eram triviais e indignos como o argumento de esnobes, que encontra expressão 
em algumas palestras ministradas por Andrew Amos em 1846, na Advanteges School, voltada aos meninos da Cidade de Londres; uma educação clássica como um auxiliar para uma Aprendizagem Comercial. Nestes, ele destacou a utilidade dos clássicos como uma habilitação "para manter o conforto e respeitabilidade da situação de um cavalheiro". No século XIX, os clássicos eram, sem dúvida considerados como a marca de um cavalheiro, mas este foi um fenômeno acidental resultante da decadência da escola secundária local e o surgimento das Escolas Públicas. Os criadores da Victorian Public School, inconscientemente, conceberam uma educação para a classe governante, eles continuaram e adaptaram o que tinha sido originalmente o tipo universal de educação. (CLARK, 1959, p. 170).

\section{Considerações finais}

Considerava-se que o mundo antigo, tinha um valor especial para o mundo moderno, porque ele era diferente, sem ser demasiado remoto. Desde a Antiguidade Clássica exemplos de grandeza individual foram utilizados para neutralizar a mediocridade da sociedade moderna e os exemplos de patriotismo e de serviço ao Estado para reprimir seu egoísmo, enquanto que a dialética rigorosa dos diálogos platônicos era um corretivo valioso à frouxidão do pensamento moderno. (CLARK, 1959, p. 171).

Esse sentido da diferença entre o antigo e o mundo moderno era algo novo, o produto do sentido histórico do século XIX e da passagem do tempo que soltou o "laço" que "amarrava" os homens à antiguidade clássica. Foi também o resultado de um maior conhecimento da Grécia, pois os gregos são mais distantes de nós do que os romanos, no entanto, foram os gregos que os vitorianos tinham principalmente em mente quando se falou do valor dos clássicos.

A importância das civilizações da Grécia e Roma na história da Europa Ocidental era inegável, seja um pensamento como o de Gladstone, do ponto de vista cristão, como proporcionando uma Evangelica Praeparatio, ou como Mill, a partir do ponto de vista secular como tendo dado à luz as ideias de liberdade 
política e intelectual, ou ainda como Matthew Arnold, um pensamento do helenismo e hebraísmo, a cultura intelectual e moral, como dois elementos que devem ser combinados em uma humanidade completa e harmoniosa. (CLARK, 1959, p. 172-173).

Finalmente, o século XIX viu o desaparecimento da antiga tradição retórica. O ideal que inspirou as escolas antigas de gramática e retórica era o do orador perfeito, bem como a ideia que inspirou seu ensino era a da eloquência. Os métodos antigos, se não os ideais antigos, passaram para as escolas humanistas. Os homens foram ensinados a escrever segundo as regras, para desenvolver um tema de forma reconhecida e para enfeitá-lo com elegantes figuras de linguagem, exemplos e símiles competentes.

Os clássicos sobreviveram apesar de todas as influências negativas do século XIX. E, nas palavras de Clark, (1959, p. 179)

(...) não é difícil imaginar a educação Inglesa tendo um tapinha diferente se, digamos, Dr. Arnold tivesse dedicado suas energias a evolução de um novo tipo de educação ao invés de ressuscitar o velho. Mas ele não fez, e o fato de que nem ele e nem outros vitorianos de alta capacidade que se dedicaram à educação não o fizeram e perderam a fé nos clássicos é um testemunho da sua vitalidade.

\section{Referências}

BEARD, M. \& HENDERSON, J. Antiguidade clássica: uma brevíssima introdução. Rio de Janeiro: Jorge Zahar Ed., 1998.

BEARD, Mary. "Learning to pick the Easy Plums: The Invention of Ancient History in Nineteenth-Century Classics". In: SMITH, J. \& STRAY, C. Teaching And Learning In Nineteenth-Century Cambridge. The Boydell Press: 2001, pp.89-106.

CHERVEL, André \& COMPÈRE, Marie-Madeleine. "As humanidades no ensino" In: Educação e pesquisa. São Paulo, jul/dez, 1999. V. 25, n. 2, p. 149-170.

CLARKE, M. L. Classical Education in Britain: 1500-1900.Cambridge: Cambridge University Press, 1959.

FINLEY, Moses. Uso e Abuso da História. São Paulo: Martins Fontes, 1989. 
MATTELART, A. NEVEU, E. Introdução aos estudos culturais. São Paulo: Parábola Editorial, 2004.

PEREIRA, Maria Helena da Rocha. Estudos de História da Cultura Clássica II. Lisboa: Fundação Calouste Gulbenkian, 1989.

THOMPSON, E. P. Os Românticos: A Inglaterra na era revolucionária. Rio de Janeiro: Civilização Brasileira, 2002.

TURNER, Frank M. "The Triumph of idealism in Victorian classical studies" In: Contesting Cultural Authority: Essays in Victorian Intellectual Life. Cambridge: Cambridge University Press, 1993.

VANCE, Norman . The Victorians and Ancient Rome. Oxford: Blackwell Publishers, 1997.

Recebido em 02 de outubro de 2013. Aprovado em 02 de fevereiro de 2014. 